\title{
LA SOMBRA DE PUSHKIN EN LA POESÍA DE V. NABOKOV ${ }^{12}$
}

\author{
Alexei Filimonov ${ }^{3}$
}

\begin{abstract}
Resumen: La sombra de Pushkin es uno de los símbolos claves de la poesía de Vladimir Nabokov. A los dos poetas les une no sólo el espacio de la literatura rusa sino también algo que la traspasa: el destino. La nostalgia de Nabokov por la Rusia perdida se une al amor que siente por Pushkin. Este trabajo presenta un estudio comparado de los temas, motivos e imágenes de la poesía de los dos poetas.
\end{abstract}

Palabras clave: Influencia, semejanza, poesía, "trasmundo", comparación.

\section{Pushkin's Shadow over Nabakov's Poetry}

Abstract: One of the most prominent symbols in Nabokov's poetry is the image of Pushkin's shadow. Both Nabokov and Pushkin are united not only by the common themes that constitute Russian literature, but also by the shared Russian concept of destiny. Nabokov's nostalgia for the lost Russia fuses with his love and admiration for Pushkin. This paper presents a comparative analysis of the themes, motives and images of the poetry of the two poets.

Key words: Influence, similarity, poetry, "otherworld", comparison.

La sombra de Pushkin es uno de los símbolos claves de la poesía de Vladimir Nabokov. Podemos decir, que es filigrana de su dádiva que se manifiesta a través de la luz del Tiempo. Parece como si Nabokov y Pushkin se comunicaran atravesando el centenario con los países y los continentes que les separaron. "Cuando lo cercano se encuentra en los siglos, siempre se convierte en algo místico. Existen otros mundos", señalaba Alexander Blok (1971: 99) en su diario. A los dos poetas les une no sólo el espacio de la literatura rusa sino también algo que la traspasa: el tema del destino, tan diferente y al mismo tiempo parecido en las señales terrestres.

"El naufragio me ha lanzado / a los países muy lejanos", confiesa Nabokov (que escribe antes de marcharse a América, en 1940, con el seudónimo de Sirin) en las líneas del poema "Petersburgo" (1921), influido por el "Arion" (1827) de Pushkin. El héroe de Pushkin en su Casita en Kolomna cuenta su sueño extraño: ¿se trata del futuro incendio en la villa de Rozhdestenno en 1995? Los sueños de "Petersburgo" nos revelan:

...la casa elevada

la miraba con desdén. Si el fuego ardiente

Fecha de recepción: mayo 2009.

Fecha de aceptación y versión definitiva: julio 2009.

2 Este artículo está traducido del ruso por Nailya Garipova, Doctoranda, Departamento de Filología Inglesa y Alemana, Universidad de Almería; $\triangle$ nailyagar@hotmail.com.

3 Miembro de la Sociedad de Escritores de Rusia y Profesor Titular de Universidad, Universidad de Gorky, Moscú, Rusia; $₫$ melosan@mail.ru. 
la abrazara de repente,

la llama agradaría

a mi mirada irritada.

A veces sueños extraños

me llegan a las entrañas.

Como si a través de estas terribles palabras a la hora de la revelación espiritual apareciera otra casa, la del final de nuestro siglo, envuelta en las llamas del infierno que para siempre hizo de Nabokov un exiliado. La nostalgia de Nabokov por la Rusia perdida se une al amor que siente por Pushkin. Al transportarse en su pensamiento a San Petersburgo, Nabokov oye la conversación de Pushkin con otro poeta, quizá sea Alexander Blok:

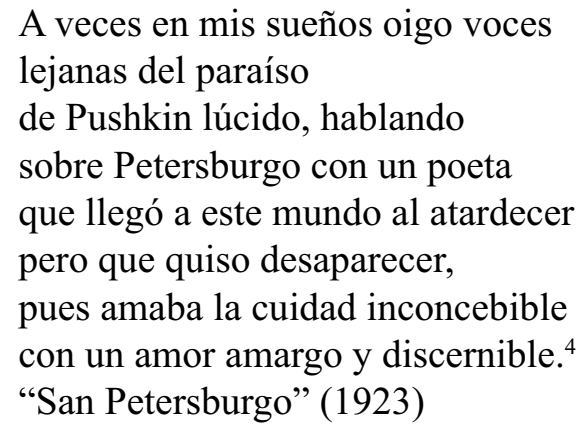

El sonido de Pushkin es como un diapasón para entonar la poesía de Nabokov. El apodo de 'poeta anticuado', como se le llama a Nabokov, enfatiza su tendencia hacia las reglas del arte noble, hacia la opinión de Pushkin sobre el lenguaje poético y la labor del poeta. "Estáis buscando las cenizas de la patria", se dirigía a sus contemporáneos el amigo y compañero literario de Nabokov, Khodasevich. Les reprochaba el intentar de encontrar la salida de la tragedia rusa en la actualidad. Nabokov, a su vez, se concentraba en lo eterno, es decir en aquello que siempre se queda con Rusia y que será la parte de su alma, en la dádiva de Pushkin. El protagonista de La dádiva, Fyodor, el alter ego de Nabokov, admira a Pushkin. Su infancia y juventud, al igual que las de Nabokov, coinciden con el florecimiento de la literatura del Siglo de Plata que produjo muchas importantes figuras literarias. "But when I tote up what has remained to me of this new poetry, I see that very little has survived and what has is precisely a natural continuation of Pushkin...", concluye Fyodor (The Gift, 139).

El no poder volver a San Petersburgo, la cuidad celebrada por Pushkin, que fue testigo de la caída del régimen antiguo, está en el pensamiento de Nabokov. Se pregunta por qué ocurrió la tragedia. Parece como si Pushkin ya hubiera predicho en su "Mednyi Vsadnik" ["Jinete de bronce"] la aparición violenta del salvaje elemento rebelde. También en el poema "Petersburgo" (1921) vemos:

¡La amada cuidad de Pushkin, en el tiempo quedó lejos!

\footnotetext{
$4 \quad$ El poema ruso está escrito en versos libres.
} 
Exclama Nabokov al recordar el esplendor del Petersburgo de su infancia. Y la cuidad, como si de un castigo se tratara, aparece ante él entre visiones sombrías:

...Se abre una fosa

en esta tumba: Petersburgo...

La capital con sus pobres esta silenciosa

y la vida por dentro es soturna y medrosa...

Sólo las sombras insomnes de los náufragos creen en el renacimiento de Petersburgo:

Ruedo por el mundo sin consuelo

sabiendo que sepulcrada está.

Revivirá un día de nuevo:

y su vida será alegre y bella,

aunque lo remoto y lo cercano

jamás podrá ser recuperado.

Dónde se esconde la respuesta a la pregunta: ¿por qué ocurrió esta tragedia? Parece que está en las líneas de "Stansy" (1827), de Pushkin: "El principio de los hechos gloriosos de Pedro / lo amargaron las ejecuciones y revueltas". Nabokov, al escrutar "la tormenta de los tiempos de las creaciones" de Pedro, descubre la historia de San Petersburgo que se esconde de los ojos de la gente ordinaria. Nos dice en el poema "Petersburgo" (1922):

...se hizo - gélido y fino,

con el son de un paso fúnebre.

En dulces sueños pensaba,

pero debajo el granito

hasta la fecha reservada

él en conciencia ocultaba

un mundo vivo y maldito.

Envuelto en neblina azulada

dormía la cuidad pasmada

y algo de repente tembló

bajo de ella - en el margal encapotado.

Todo empezó a trepidar, sonando miles aullidos,

y al abrirse el abismo quiso dar

a encantados fallecidos.

El jinete de bronce se movió

y se ofuscó la bóveda celeste.

Un gran grito de victoria se oyó:

"que viva mucho el demonio palustre". 
Estos “demonios palustres", bastante reservados y pacíficos en aquellos tiempos cuando Alexander Blok componía su ciclo de pomas Puzyri zemli [Burbujas de tierra] (1904-1905), de repente se despertaron y empezaron a rehacer el mundo. Una calina rencorosa cubrió el cielo de San Petersburgo y de Rusia. ¿Qué podía hacer Nabokov? "Suspirar por la Rusia sombría", como lo hizo Pushkin, en su poema "Exilio" (1925). Nabokov le traslada a Pushkin al mundo de la emigración en este poema:

Quizá con la ternura y con la ira, como una ave grandiosa volaría, con una sorprendente melodía que se iba a propalar por todo el mundo.

Puede que otro sea: en la proscripción, realizando su peregrinación él preferiría abrocharse con paciencia en su intensa alma la capa de prudencia.

Parece como si Pushkin siempre estuviera presente en Nabokov. "Pushkin es arcoíris de todo el mundo", - exclama Nabokov en su poema "Na smert' Bloka" ["A la muerte de Blok"]. Aquí, Nabokov identifica el eslabón que siempre reúne las piezas de la "pléyade aislada": a Lermontov, Tyutchev, Fet, Blok, Bunin. Y, por supuesto, a N.Gumilev, cuyo fusilamiento para Nabokov se ha unido con la muerte de su padre. En "Hexámetros", dedicados a la muerte de Gumilev, también aparece la sombra de Pushkin. Las almas se encuentran en los Campos Elíseos y recuerdan las señales de la vida terrestre:

Has muerto con soberbia y claridad, como te enseñaba la Musa.

Ahora en la calma de Elíseos contigo conversa

sobre el jinete de cobre y los vientos africanos - Pushkin. ${ }^{5}$

"Puro y alado" así define Fyodor su dádiva en el extranjero. Los poemas de NabokovSirin también son alados, ligeros. Así aparece Pushkin en sus sueños. Así de sonora y armoniosa fue la vida de Pushkin o el mito sobre ella. Nos dice en el poema "Tolstoi" (1928):

Pushkin es otra cosa: capote, roca, espuma del mar...

La palabra 'Pushkin'se cubre de poemas como de hiedra,

y la musa repite los nombres que resuenan alrededor de él:

Delvig, Dansas, Dantes y dulcísona

toda su vida, desde Demia del instituto

hasta el disparo en el frio día del duelo.

Se equivocaba Nabokov cuando pensaba que no le recordaría nadie en su país natal. Y Tunguso, y Kalkmuko (véase The Gift, 311) leen sus obras ahora. Su poema "Fama"

\footnotetext{
5 En ruso el poema está compuesto en versos libres.

6 Aquí traducimos la frase al español, ya que no hay el mismo juego de palabras y sonidos en la versión inglesa.
} 
(1942), que alude al "Profeta", es, en cierto modo, su anti-profecía. Lo único que sí se cumplió, es que el secreto de la obra de Nabokov, es decir, su enigma, sigue siendo igual de quimérico y seductor. Lo mismo pasa con Pushkin: cuanto más lo conocemos, más nos parece enigmático e inconcebible. Nabokov es uno de sus espejos dobles que mira a través del hombro de Pushkin y allí esta "examinando algo / a través del hombro invisible".

El siglo de Nabokov, lleno de ideologías, resalta la frescura intacta de la poesía de Pushkin. Esta poesía inspira a Nabokov y a su héroe, Fyodor: "here is a theme for you... the poet himself chooses the subjects for his poems; the multitude has no right to direct his inspiration”. ¿Qué es ser poeta? ¿Qué lugar y que destino tiene él en la vida? Estas son eternas preguntas. Como Pushkin, Nabokov también intenta encontrar las respuestas. Así aparece el poeta delante del improvisador de Las Noches egipcias:

Él camina, los parpados abiertos,

sin ver a nadie, pero sin embargo,

mientras que en nada piensa, un caminante

le tira de la manga en ese instante.

Es verdad que a veces un poeta es "raro" ante las miradas de la gente "normal". Puede ser que es la ofrenda sagrada inmolada para el arte, para la eternidad o para los lectores indefinibles. Esta ofrenda le traslada a otra dimensión, como pasa con el ajedrista Luzhin, que se aleja hacia los precipicios del ajedrez, más allá de la realidad. Allí, estando en la "niebla pulsante" el artista encuentra su integridad.

La "Sincronización cósmica" (Nabokov, 1996: 49), la definición de Nabokov, algo ponderable, indica la pulsación en donde se concentra el secreto del poeta, el secreto de "sentir todo lo que ocurre en el punto del tiempo" (Nabokov, 1996: 49). El poeta de Pushkin, recreado en un profeta, recibe este don. El poema de Fyodor (La dádiva) "Only what is fanciful and rare" también habla del tiempo cósmico, que recoge en un único manojo la visión de un poeta: "beyond that gate lies Baghdad's crooked shade, and yonder star sheds on Pulkovo its beam" (The Gift, 145-6). Aunque Fyodor está en Berlín, es capaz de retroceder hacia Rusia: "there water gleams, there Venice vaguely shows. Look at that street - it runs to China straight and yonder star above the Volga glows" (The Gift, 164).

"Dios, no dejes que pierda la razón", escribía Pushkin, refiriéndose a la locura de Batyushkin, que para siempre se marchó al mundo de las dulces melodías, o a Chadaev, al que la gente le declaró insensato. "It was a conversation with thousands of interlocutors, among which only one was real", confiesa Fyodor en su intento de escapar del caos de las voces hacia lo único que vale la pena. ¿Y si éste desaparece o no existe? Entonces, la comprensión de su propia grandeza es también irreal. Esto recrudece la ruptura entre la vida imaginaria, en la que el poeta gracias a su propia grandeza es "Tamerlan o Napoleón" (Pushkin), y la vida humana, en la que él es insuficiente y lo rechazan por ser insólito. El poeta desafía los elementos y, ante todo, la rutina humana. "O swear to me to put in dreams your trust, and to believe in fantasy alone, and never let your soul in prison rust, nor stretch your arm and say: a wall of stone" (The Gift, 164): así se dirige el protagonista de La dádiva a su Mnemosina. 
En esta duplicidad, el poeta, ante todo, es una persona, que puede adoptar la máscara de un poeta, pero jamás será un poeta de verdad. Lo mismo pasa con el poeta, pues aunque aspire al mimetismo en medio de las personas ordinarias, siempre será marginado, como Cincinnatus o como Improvisador. Aquí es donde vemos el límite del heterodoxismo autentico. Nabokov analiza la mente de los insensatos que pretenden la corona poética, en su poema "El loco" (1933). "Tantos años estando encerrado", señala refiriéndose a la posición de un hombre encerrado en si mismo, con un aislamiento que puede ser involuntario o intencionado. Y esta es la tragedia de este hombre. Por eso considera la idea de voluntad humana y creativa: "quiero ser distinto, / un carpintero, un modisto". Pero él se queda balanceando en un frágil límite entre los mundos ilusorios: entre el arte y la vida, incapaz de asimilarlos y unirlos.

Los quince largos años de la traducción y el comentario de Eugeni Onegin le permitieron a Nabokov crear una obra única, como si Pushkin le alimentara línea tras línea con su lenguaje. Recordamos las quejas de Nabokov por la lejanía de su lengua materna en su "Poema de la universidad" (1927):

Los años pasan y mi lengua dada está escaseando, ya no es la misma.

A gran distancia de mi patria amada, palabras, como Rusia y sus orillas desaparecen en la lejanía.

Traducir a Pushkin y otros poetas rusos le permitieron a Nabokov estar en Rusia y respirar el aire del bosque de Petersburgo saciando sus pulmones y su sangre. Puede ser que Nabokov afinara su obra como un entomólogo literario al estudiar cuidadosamente el derecho y el revés de la materia del mundo, su relieve, sus rupturas que traslucen el "trasmundo", sus matices y sus imágenes fantasmagóricas, al estudiar los detalles escondidos entre las líneas de la poesía de Pushkin. Su compasión hacia la materia, su manera de tratarla como un ser vivo son admirables. Su materia no está condicionada por la separación de la gente, sino por un principio religioso: en el mundo isométrico no existen detalles insignificantes ni en la naturaleza ni en el mundo alrededor.

"Existe un encanto en la lucha / y en el borde de la sima oscura", hablamos de la sima sombría de la mente humana. Por romper el precipicio de la conciencia o por traspasar las dimensiones el poeta paga con su locura o marginación. A veces paga un precio más elevado: la muerte. Es el caso de Martín de La hazaña, o de muchos héroes de los poemas que realizan su peregrinación a ninguna parte: hacia la realidad imaginaria viajando por la poesía de Nabokov en "Fusilamiento" (1927):

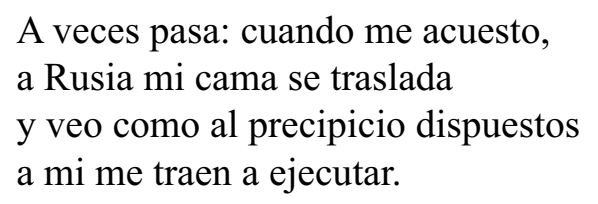


sintiendo otra vez con mucha fuerza

mi proscripción que es afortunada.

El corazón así me dice: "lo quiero, y que todo eso sea cierto:

mi Rusia, el disparo...el cielo

y el barranco lleno de cerezos".

La aspiración de Pushkin hacia la pureza eterna, sus elementos angélicos, su "monasterio en el Cáucaso", todo se encuentra reflejado en la obra de Nabokov. Sus personajes están cansados de despertarse de los sueños que les llevan al paraíso de Rusia, y encontrarse en la realidad letárgica. "Nos queda ajedrez, Shakespeare y Pushkin. No hace falta nada más", le dice el poeta a su Mnemosina, mirando a su alrededor y viendo un paisaje desolador: no hay ni gente ni almas, como si se las llevaran los demonios, tomándolas en sus brazos como las hojas del otoño.

Nabokov -que a menudo insistía en su rechazo a las tradiciones humanistas de la literatura de las "raznochinetz"- en su poesía aparece sentimental y se muestra abierto a la desgracia de los demás. Lo podemos ver en su "Poema de Paris" (1943) en el que pide compasión hacia sus compatriotas abandonados en el extranjero. Como Pushkin: "Y pedia piedad para los muertos", "Pamyatnik" [ "El monumento"]:

Llévatelos, no los dejes.

Esta gente ama Moscú.

Y cuida de este granuja:

que era un ángel como tú.

Toda la banda, ¡qué cuellos horrorosos, como los ancianos en la hoguera ajena! ¡Señores, como sois muy bondadosos, apiádense porque merecen su pena!

A veces en los poemas de Nabokov aparece el epíteto favorito de Pushkin: 'oblongos', como los ojos de Shakjerizada, de Nabokov que aluden a Pushkin: "oblonga y transparente uva", como los dedos de la doncella. El arte y la realidad, entrelazados rara y elegantemente, se reflejan en la obra de los dos poetas.

Siguiendo con el tema de los mundos, la eternidad y lo imaginario, podemos distinguir una semejanza más entre la poesía de Pushkin y la de Nabokov. Por ejemplo, el reflejo de "La estatua jugando a las tabas" y "La estatua jugando al svaica" (ambos del 1836) de Pushkin, y en los poemas "Football" y "Lawn-tennis" (ambos del 1920) de Nabokov. Pushkin imprime un instante del pasado en las antiguas estatuas de los jóvenes, como si ellos revivieran jugando delante de sus ojos, regresando de la inmortalidad hacia la tierra. Uno de los jugadores de Nabokov, después del juego se marcha fuera del tiempo. Aquí,

\footnotetext{
Un juego ruso muy antiguo.
} 
Nabokov es el poeta que quita su envoltura terrestre y entrega su alma a sus héroes. En su poema "Football" (1920) nos dice:

El balón saltaba sin que tu supieras
que uno de los jugadores descuidados,
creaba al atardecer en el silencio
la armonía de los tiempos olvidados.

Las semejanzas entre las vidas de Nabokov y Pushkin, sus señales secretas, a veces con arabescos paradójicamente similares, siempre le han preocupado a Nabokov: "San Petersburgo - helada blanca adornada, / sombra transparente de época pasada". ¿A qué sombra se refiere? Puede que a la sombra del amor frustrado del joven Nabokov o a la sombra de Pushkin, que se hace más inmenso con el paso del tiempo.

“¿Y si Pushkin estuviera entre nosotros, / un exiliado como tú y yo?”, le pregunta Nabokov no sólo a su contemporáneo pero también a los poetas futuros. En cierto modo, él desarrolla esta idea en La dádiva, y nos pregunta: ¿Qué le podríamos decir a Pushkin que vive entre nosotros? ¿Le podríamos pedir elogios? O podríamos preguntarnos a nosotros mismos si estamos satisfechos con nuestra labor de creadores de palabras.

Otro punto de similitud entre los dos poetas lo encontramos en su pasado: su infancia entre la Crimea real en la que se acabó la Rusia de Nabokov y la Crimea inmemorable con su fuente de Bajchisarái. Oímos la "canción verdadera de la poesía" de Pushkin en el poema de Nabokov "Crimea” (1920):

En la entrada el manantial goteaba, el manantial de tristeza agradable, con el cuento eterno murmureando en el silencio nocturno y palpable. La estrella fugaz cayó sobre el bosque. De pronto se puso junto a mí Pushkin y con claridad empezó a sonreírme.

La magia de Pushkin está en su poesía, en su claridad, armonía y universalidad. Lo mismo ocurre con la magia de Nabokov. La viuda del poeta, Vera Evseevna, hablaba de su secreto en el prologo de su colección póstuma de poemas Stiji, llamándolo "trasmundo": “...estaba comprometido con este secreto durante muchos años de su vida, casi sin darse cuenta de ello; y este secreto, esta magia le daba su imperturbable alegría de vivir y su lucidez hasta en las situaciones mas difíciles haciéndolo absolutamente invulnerable para varios ataques, tontos o premeditativos". Parece que Nabokov sentía la luz de las líneas de Pushkin. "Porque está cerrado del todo y es imposible de quitarlo", escribía él en el poema "Como te quiero" (1934). Pushkin siempre ha estado entreabierto para la mente de Nabokov. Pushkin le acompañaba durante los años del exilio. Durante este tiempo había encuentros inesperados y llenos de alegría. Por ejemplo en Cambridge: "He encontrado a Pushkin y a Dal / En un anaquel encantado", recuerda él en su "Universitetskaya poema" ["Poema de la universidad"] (1927). 
En 1942, en América, Nabokov escribió su versión de la última escena de Sirenita de Pushkin. "Pushkin se encoge de hombros", observación de Nabokov antes de ponerle el punto final. No sabemos que le respondería Pushkin sobre la escena añadida, si lo hubiera encontrado a Nabokov en el limbo al lado de Neva. Puede ser que este encuentro sí tuvo lugar y Nabokov dejó una breve constancia de ello, sin revelarnos el contenido de la conversación:

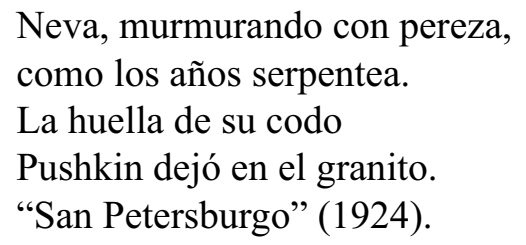

El lugar del encuentro es una ciudad divina, capricho de dios o del demonio. Parece que entre la belleza fría y perfecta de San Petersburgo aparecen las líneas de Pushkin, llenas de armonía y perfección inhumana: "San Petersburgo - escarcha adornada / Ex libris del demonio, quizás..."

Es importante prestar atención a la palabra "escarcha" en el vocabulario poético de Nabokov. "Y el abeto a través de la escarcha verdea", escribía Pushkin en el poema "La mañana invernal" (1829). La escarcha de Nabokov es doblemente transparente. Es el frio aliento del trasmundo, a través del cual aparece otra realidad. "Veré al escarchado Isaac" y él retrocede a través de los kilómetros a su cuidad natal en el poema "El salto del esquí" (1926). La catedral de Isaac envuelta en escarcha azulada parece encantada por el velo de los sueños que pululan alrededor de ella. En el poema "Isjod" [“El fin"] (1924) Nabokov sigue con la mirada la catedral y al jinete de bronce, que pasaban no se sabe dónde "en asombro sobrenatural", y distingue los fantasmas de los arboles viejos, envueltos en la escarcha del silencio: "al dios llevaban su escarcha pura los fantasmas de los arboles exánimes". La escarcha de Nabokov es la niebla enfriada por la eternidad, languidez de la vida, es la nube empañada en el cristal mágico que protege la mente humana de escudriñar el futuro. dad:

Al evaporarse, la escarcha se lleva consigo la esperanza de obtener la patria en reali-

Se levantaron y a través de la planada para siempre se marcaron en oscuridad:

Visión, escarcha, la faz sagrada sin dejarnos ni rastros de maldad...

"Videnie" [ "Un espectro"] (1924)

¿Qué le queda al exiliado en el país extranjero? Le queda el espacio del sueño, la dimensión de la dádiva entre las crecientes pérdidas. Nabokov-Sirin exclama:

Doy gracias al poder sagrado,

por ver a los muertos soñando.

$¡ O$, como mi alma agitada

se engalla de este sueño extraño!

"Snovidenie" [ "El ensueño"]1927 
En sus sueños se encuentra con las apariencias de sus allegados, entre ellos, quizás, con su padre Vladimir Dmitrievich Nabokov: "Reconozco / Tu paso animosos / no has cambiado desde tu muerte" ("La tarde en el solar" 1932).

A menudo el mundo de las obras de Nabokov lo denominan fantasmagórico. Por eso, a la mente ordinaria le puede parecer demasiado frio y transparente. Detrás de él se esconde la realidad de los recuerdos y sueños, de donde Nabokov extrae su fuerza. Lo mismo ocurría con Pushkin, que en los momentos del conjuro nocturno, llorando por la sombra querida, creaba una fuerza ardiente que derretía la escarcha de las losas sepulcrales:

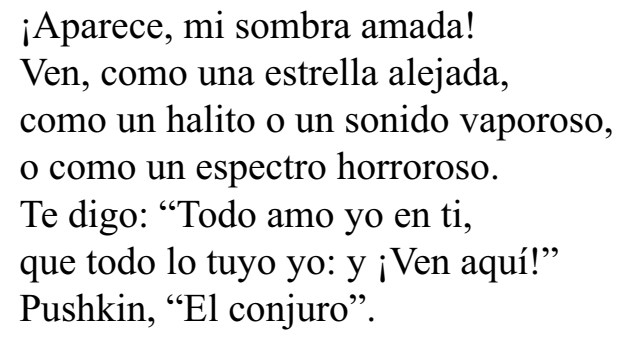

"La sombra transparente de los días futuros", así Nabokov llama los reflejos de Pushkin en las noches blancas de Petersburgo. Es aquel espacio, donde no existe la cuenta del tiempo, ya que el tiempo es único para todos los que entran en este espacio - el poeta y sus lectores. En realidad, es el espacio lo que une a toda la humanidad. "La cuidad portuaria... trasladada al paraíso" recibe las almas rendidas. En esta cuidad revive todo aquello que antes parecía ser un caos:

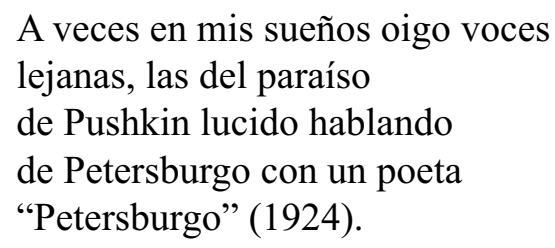

Y la casa, -secuestrada por las olas del olvido, en "Jinete de bronce" o reducida a cenizas por el incendio, que de repente se encendió en la mente del poeta en la La casita en Kolomna- empieza a revivir, reconstruirse y tener nuevos inquilinos. Como si el país extranjero ya no existiera: "behind the public garden a house was being built, he could see the yellow wooden framework of beams - the skeleton of the roof, which in parts was already tiled" (Mary, 135), apuntaba Nabokov en su primera novela. Así, al convertirse en un museo, revive la casa donde nació y se reconstruye su villa:

Nuestro hogar en el extranjero, en que duerme el proscrito sosegado, siempre por Rusia será rodeado:

Por el mar, el secreto y por el viento pasajero

De este modo lo reconoce con alegría Nabokov en el poema "La patria" (1927). Hoy en día Nabokov y Pushkin se encuentran en el espacio de San Petersburgo. ¿Sobre qué hablan? 
Nosotros, -los que intentamos entreabrir el telón que separa a los vivos de los habitantes del mundo de las sombras- no lo podemos adivinar. Pero, quizás, ellos sí nos oyen...

\section{REFERENCIAS BIBLIOGRÁFICAS}

BLoK, A. 1971. Собрание сочинений в 6-ти томах. Moscú.

Dolinin, A. 2007. “Три заметки о романе В. Набокова Дар”. В.В. Набоков: Pro et contra. Личность и творчество Владимира Набокова в оченке русских и зарубежных мыслителей и исследователей. Антология. San Petersburgo: Русский Христианский гуманитарный институт. 697-740.

NAвокоv, V. 1916. Стихи. Петроград: Худож.-графич. Заведение Унион. . 1918. Альманах: Два пути. Петроград: изд. инж. М.С. Персона. . 1923. Гроздь. Berlín: Гамаюн. . 1923. Горный путь. Berlín: Грани. . 1930.Возвращение Чорба: Рассказы и стихи. Berlín: Слово. . 1951. Стихотворения. París: Рифма. . 1959. Poems: Garden City. Nueva York: Doubleday. . 1971. Poems and Problems. Nueva York: McGraw-Hill. . 1979. Стихи Анн Арбор. Мичиган: Ардис. . 1996. “Первое стихотворение”. Звезда. № 11.49. . 1999. Собрание сочинений в 5-ти томах. San Petersburgo: Симпозиум.

Stark, V. 1997. "Пушкин в творчестве В.Набокова". В. Набоков: Pro et contra. Личность и творчество Владимира Набокова в оченке русских и зарубежных мыслителей и исследователей. Антология. San Petersburgo: Русский Христианский гуманитарный институт. 780. 